\title{
$\underline{\text { Nucleolar Stress Induction by Oxaliplatin and Derivatives }}$
}

Emily C. Sutton ${ }^{\#, t, \ddagger}$, Christine E. McDevitt ${ }^{\#, \S}$, Jack Y. Prochnau ${ }^{\S}$, Matthew V. Yglesias ${ }^{\ddagger \S}$, Austin M. Mroz ${ }^{\S I}$, Min Chieh Yang ${ }^{\S I}$, Rachael M. Cunningham ${ }^{\S}$, Christopher H. Hendon ${ }^{\S}$, Victoria J. DeRose ${ }^{*}, \ddagger$ II

${ }^{\dagger}$ Department of Biology, ${ }^{\ddagger}$ Institute of Molecular Biology, ${ }^{\S}$ Department of Chemistry and Biochemistry, II Materials Science Institute — University of Oregon, Eugene, OR 97403

\#Co-first authors

\section{Table of Contents}

\begin{tabular}{|c|c|}
\hline $\begin{array}{l}\text { Supplementary Figures and Tables } \\
\text { Supplementary Figure } S 1 \ldots \ldots \ldots \ldots \ldots\end{array}$ & $\begin{array}{l}\text { Page Number } \\
\ldots \ldots \ldots \text { S2 }\end{array}$ \\
\hline Supplementary Figure S2.............. & ...........S3 \\
\hline Supplementary Figure S3.. & ..S4 \\
\hline Supplementary Figure S4.. & ..S5 \\
\hline Supplementary Figure S5.. &. .56 \\
\hline Supplementary Table S1.. & $\ldots S 7$ \\
\hline Supplementary Table S2.. & $\ldots S 8$ \\
\hline Supplementary Table S3. & .89 \\
\hline
\end{tabular}

\section{Materials and Methods}

Cell culture and treatments............................... 10

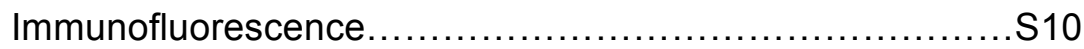

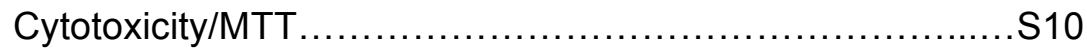

Image processing and quantification........................ 10

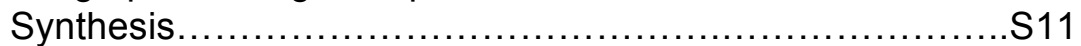

Measurement of partition coefficients......................... 13

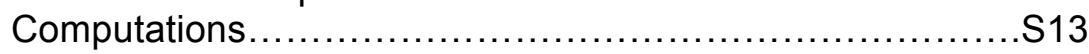

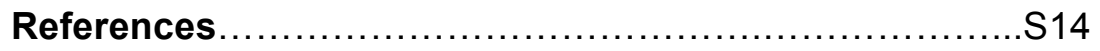




\section{Supplementary Figures:}

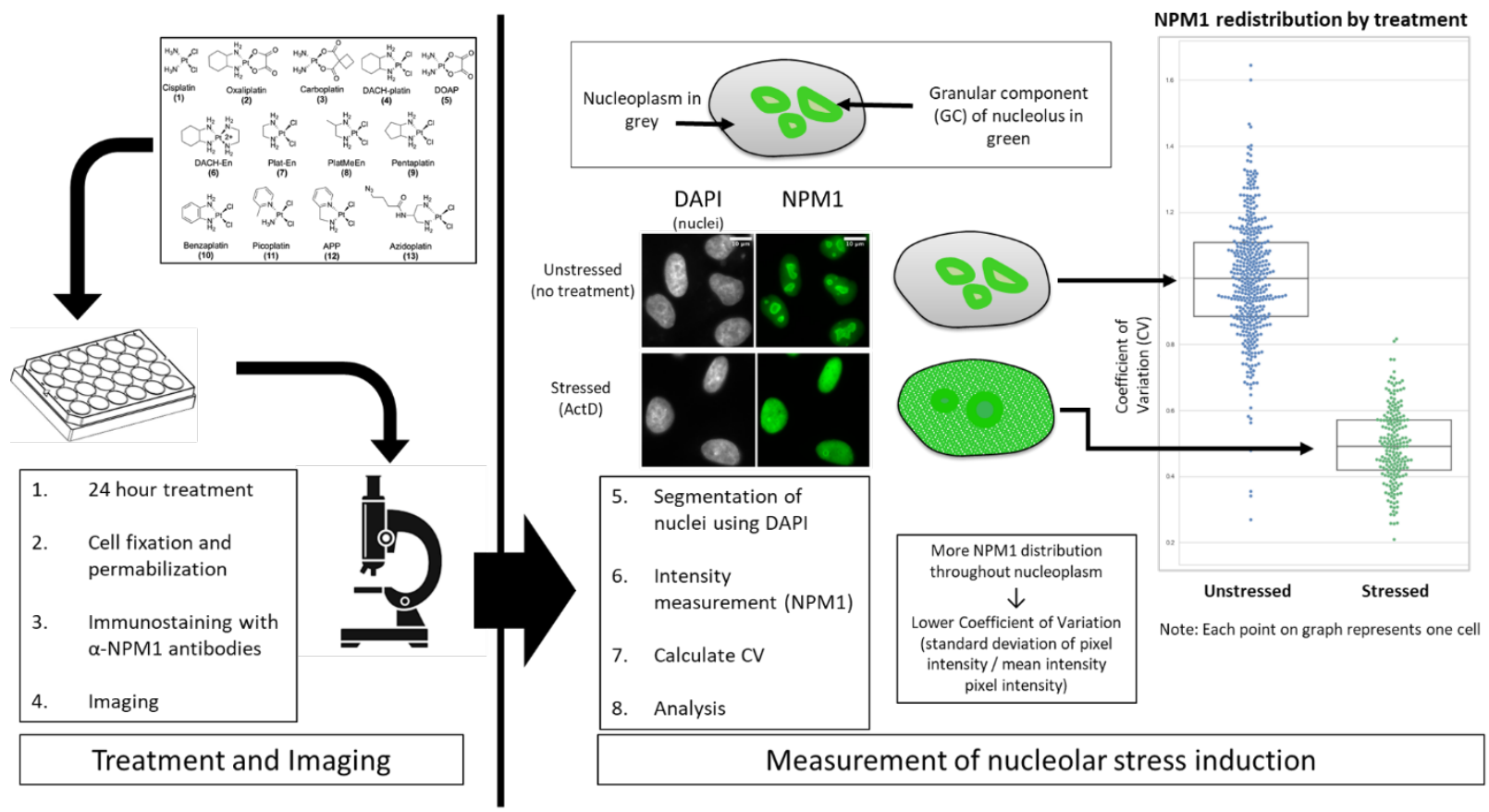

Supplementary Figure S1. NPM1 assay and quantification scheme. A549 cells were seeded on coverslips treated for 24 hours with the selected compound. Cells were fixed, permeabilized, and stained with an a-NPM1 antibody as described in Materials and Methods section. After imaging, nuclei were segmented using DAPI staining and pixel intensity from NPM1 imaging was measured. The Coefficient of Variation (CV, standard deviation over mean), was calculated for each nucleus, normalized to the mean $\mathrm{CV}$ for the no treatment control on that day, and plotted as above with each nucleus represented by one point on the plot. An average CV of 1.0 indicates no stress, whereas a lower CV (around 0.6) indicates diffusion of NPM1 throughout the nucleoplasm, a positive indicator of nucleolar stress. Treatment data sets are represented by box plots, where the center, top, and bottom lines of boxes represent the median, first and third quartile respectively. 

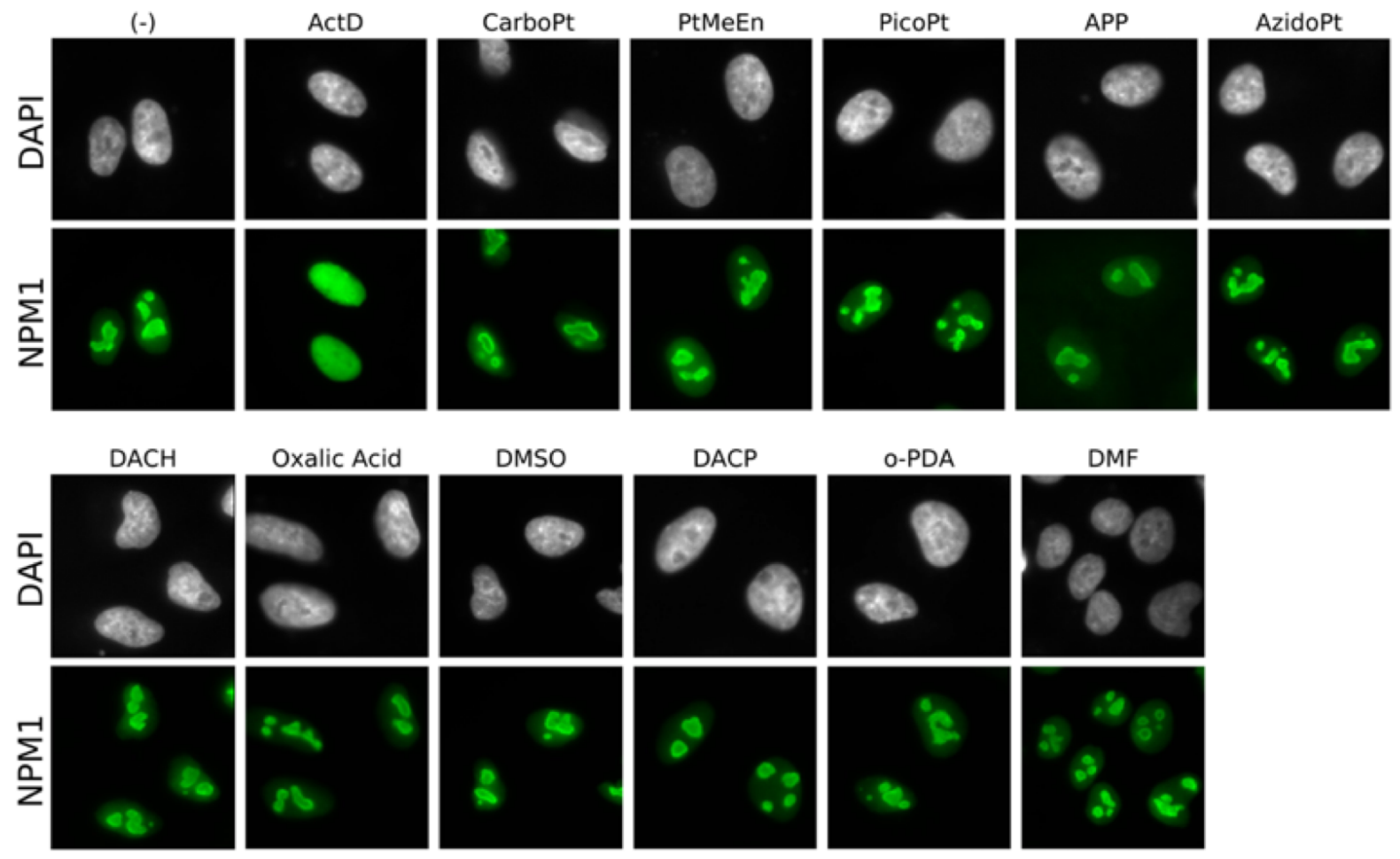

O-PDA
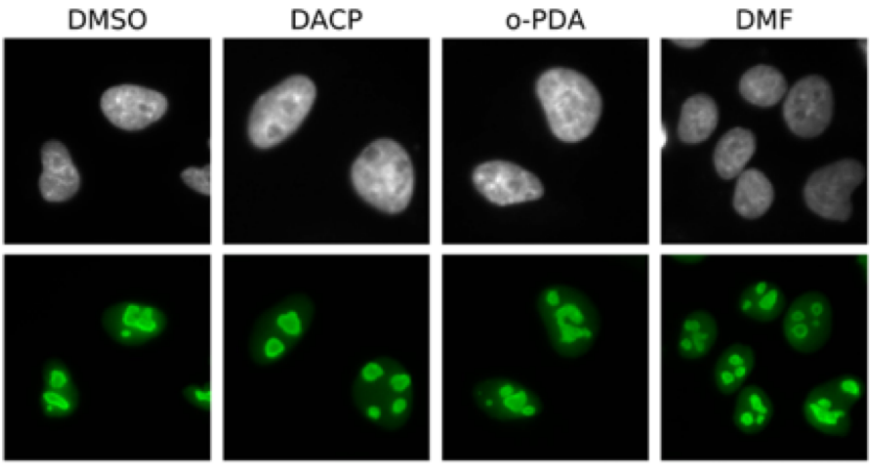

Supplementary Figure S2. Additional images for compounds tested. Top row shows negative and positive (Actinomycin D) controls, and $\mathrm{Pt}(\mathrm{II})$ compounds 3, 8, 11, 12, and 13, respectively CarboPt, PtMeEn, PicoPt, APP, and AzidoPt - none of which caused nucleolar stress. Bottom row shows $\mathrm{Pt}(\mathrm{II})$-free ligands of stress-inducing $\mathrm{Pt}(\mathrm{II})$ compounds and solvents used (DMSO and DMF). Ligands alone do not induce nucleolar stress, and neither do solvents. All treatments were performed for 24 hours. $\mathrm{Pt}(\mathrm{II})$ compound and ligand treatments were conducted at $10 \mu \mathrm{M}$, with the exception of Actinomycin $\mathrm{D}$, which was $5 \mathrm{nM}$, and 3 (CarboPt), which was $20 \mu \mathrm{M}$. DACP = 1S,2S-diaminocyclopentane, o-PDA = o-phenylenediamine. 


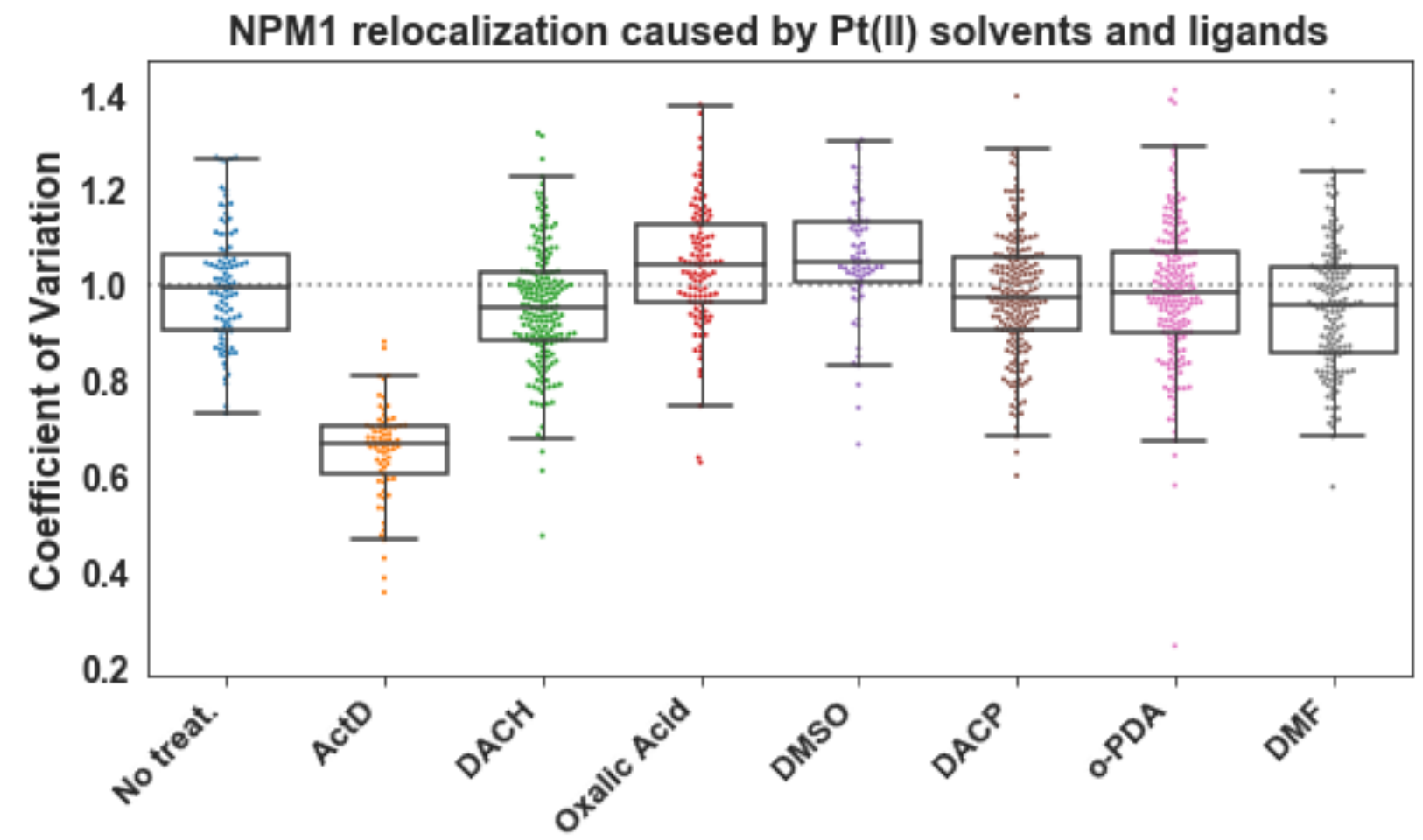

Supplementary Figure S3. Quantification of nucleolar stress induction for Pt(II)-free ligands and solvents used. CV quantification confirms that ligands alone do not induce nucleolar stress, and neither do solvents. All treatments were performed for 24 hours. Treatments were conducted at $10 \mu \mathrm{M}$, with the exception of Actinomycin D, which was $5 \mathrm{nM}$. DACP $=1 S, 2 S-$ diaminocyclopentane, o-PDA $=0$-phenylenediamine. Treatment data sets are represented by standard box plots, where the center, top, and bottom lines of boxes represent the median, first and third quartile respectively. The vertical lines represent the range of data within 1.5xIQR of the lower and upper quartiles, where IQR is the difference between first and third quartile; points outside this range are considered outliers. 


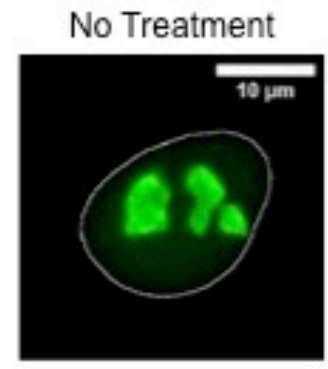

Cisplatin

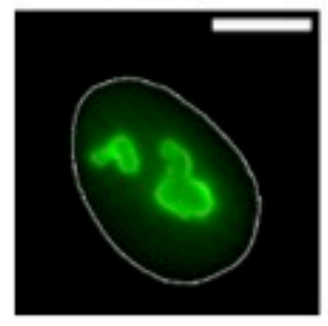

Oxaliplatin


Pixel intensity

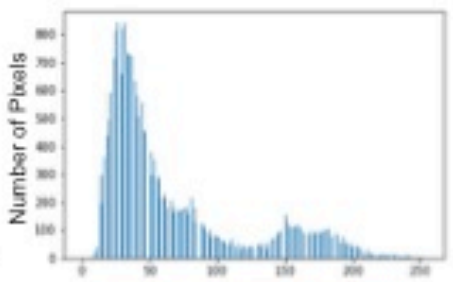

Pixel intensity

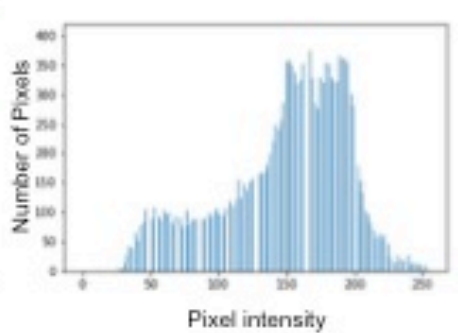

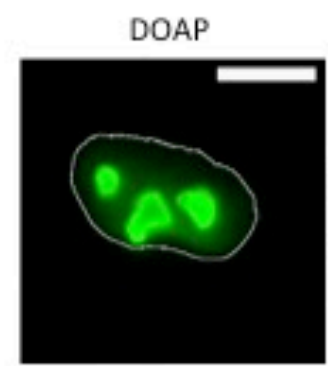
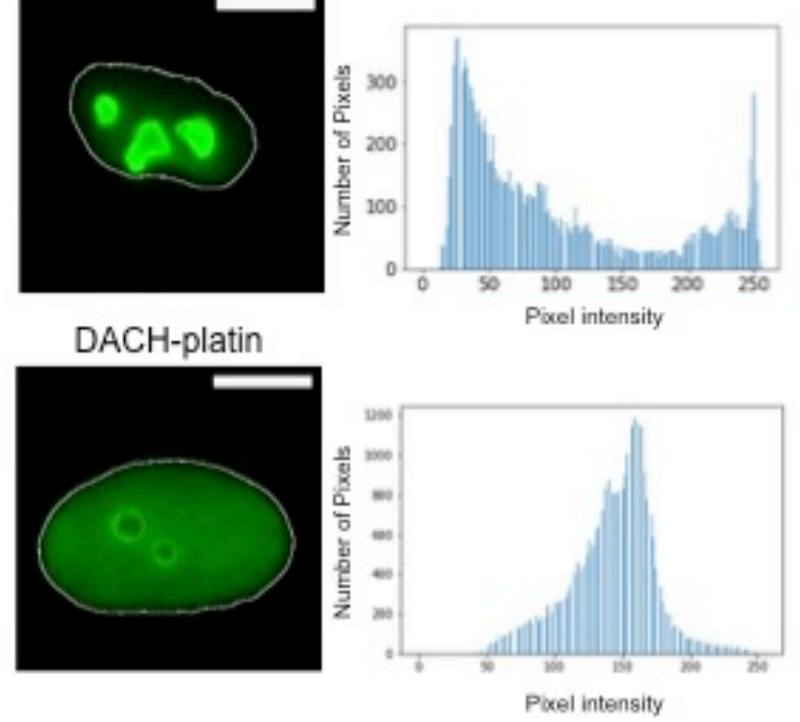

Supplementary Figure S4. Histograms showing NPM1 intensity within a single nucleus in stressed and unstressed cells. $X$ axis represents pixel intensity, and $Y$ axis represents the number of pixels within a nucleus of the intensity on the $X$ axis. Cells not undergoing nucleolar stress have a large number of low intensity pixels and a small number of high intensity pixels, indicating NPM1 is concentrated in the granular component of the nucleolus. Cells undergoing stress have a broader distribution of pixel intensities, with the histogram skewing towards high intensity, as NPM1 has redistributed throughout the entire nucleoplasm. 

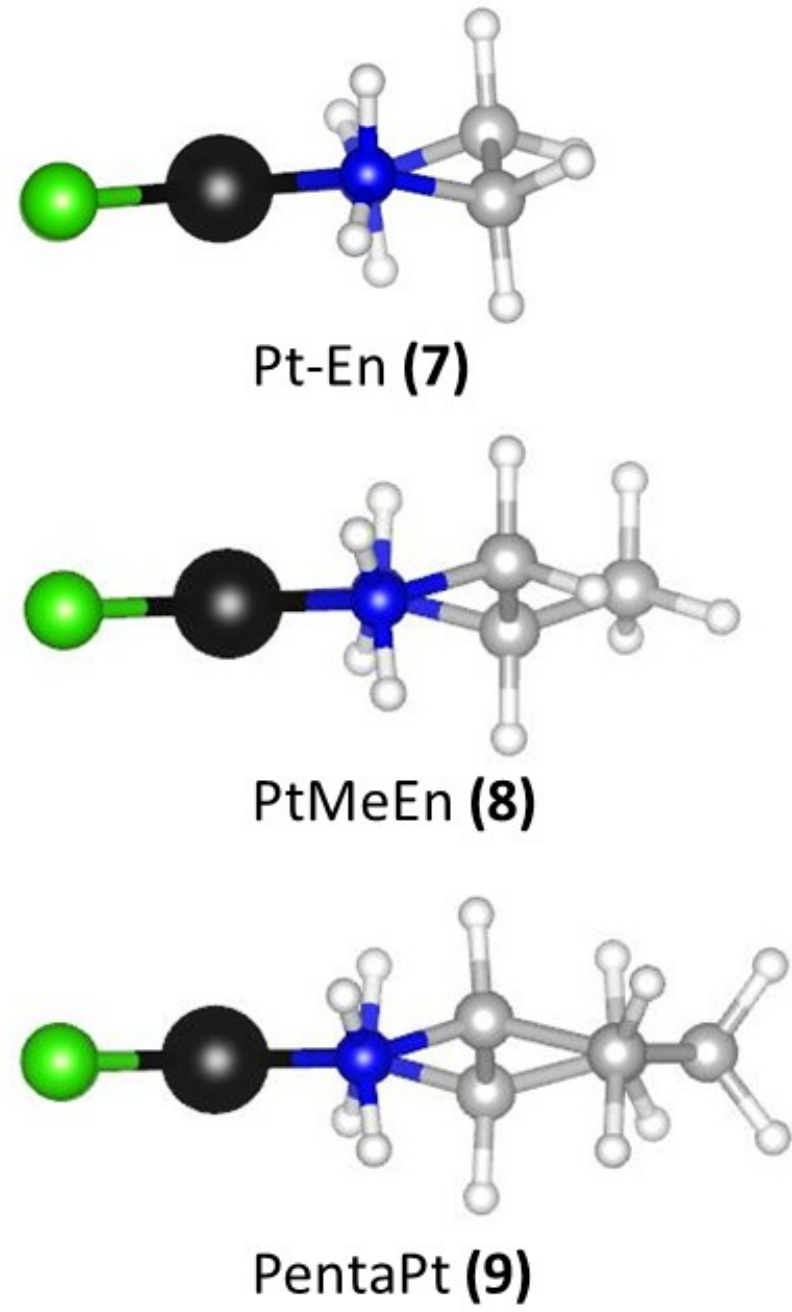

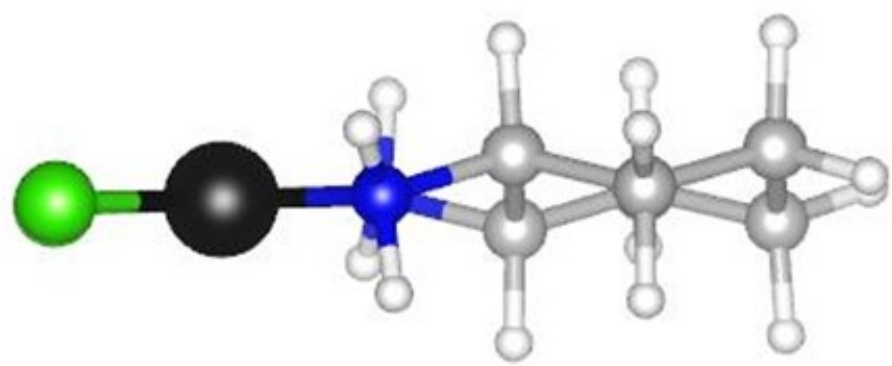

DACH-Pt (4)

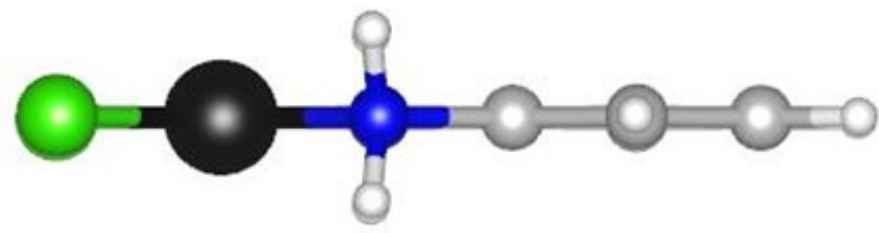

BenzaPt (10)

Supplemental Figure S5. DFT-optimized structures of compounds illustrating the relative size of compounds and planarity of BenzaPt 10 relative to DACH-Pt 4 


\section{Supplementary Tables:}

Table S1. IC 50 values in A549 cells for selected compounds at 24 hours ${ }^{a}$

\begin{tabular}{cc} 
Compound & $\mathrm{IC}_{50}(\mu \mathrm{M})$ \\
\hline Oxaliplatin, $\mathbf{2}$ & $81.5 \pm 7$ \\
Cisplatin, $\mathbf{1}$ & $12.8 \pm 2$ \\
DACHplatin, $\mathbf{4}$ & $31.9 \pm 6$ \\
Pentaplatin, $\mathbf{9}$ & $37.5 \pm 5$ \\
Benzaplatin, $\mathbf{1 0}$ & $\mathrm{NR}^{\mathrm{b}}$ \\
PlatEn, 7 & $46.1 \pm 6$ \\
PlatMeEn, 8 & $76.1 \pm 9$ \\
DOAP, $\mathbf{5}$ & $36.6 \pm 5$ \\
APP, $\mathbf{1 2}$ & $\mathrm{NR}^{\mathrm{b}}$
\end{tabular}

${ }^{a} \mathrm{IC}_{50}$ values in A549 cells were determined after 24-hour treatment with indicated compound ${ }^{\mathrm{b}} \mathrm{NR}=\mathrm{IC}_{50}$ value not reached, $>500 \mu \mathrm{M}$ 
Table S2. IC I0 $_{50}$ alues in A549 cells for selected compounds at 48 hours ${ }^{\mathrm{a}}$

\begin{tabular}{cc} 
Compound & $\mathrm{IC}_{50}(\mu \mathrm{M})$ \\
\hline Oxaliplatin, 2 & $9.9 \pm 3.5$ \\
Cisplatin, 1 & $4.6 \pm 0.7$ \\
Benzaplatin, 10 & $6.9 \pm 0.7$ \\
APP, 12 & $36.9 \pm 4.3$
\end{tabular}

${ }^{\mathrm{a}} \mathrm{IC}_{50}$ values in A549 cells were determined after 48-hour treatment with indicated compound 
Table S3. Volume and hydrophobicity data

\begin{tabular}{cccc} 
Compound & Volume $\left(\AA^{3}\right)$ & Distance $(\AA)$ & $\log P$ \\
\hline Cisplatin & 19.46 & 3.40 & $-2.39 \pm 0.005$ \\
PlatMeEn & 23.56 & 5.51 & $-1.68 \pm 0.014$ \\
PlatEn & 21.47 & 4.41 & $-1.85 \pm 0.013$ \\
APP & 27.66 & 6.21 & $-1.1 \pm 0.058$ \\
Picoplatin & 27.69 & 6.21 & - \\
Pentaplatin & 27.85 & 6.21 & $-1.29 \pm 0.031$ \\
Benzaplatin & 28.71 & 6.73 & $-0.92 \pm 0.038$ \\
DACH-platin & 30.01 & 6.75 & $-0.89 \pm 0.011$ \\
Carboplatin & 30.94 & 6.30 & - \\
DACH-En & 32.41 & 6.72 & - \\
Azidoplatin & 32.71 & 13.16 & $-1.2 \pm 0.059$ \\
Oxaliplatin & 34.13 & 6.78 & $1.58 \pm 0.02$
\end{tabular}




\section{Materials and Methods:}

\section{Cell culture and treatment}

A549 human lung carcinoma cells (\#CCL-185, American Type Culture Collection) were cultured at $37^{\circ} \mathrm{C}, 5 \% \mathrm{CO}_{2}$ in Dulbecco's Modified Eagle Medium (DMEM) supplemented with $10 \%$ Fetal Bovine Serum (FBS) and 1\% antibiotic-antimycotic. Treatments were conducted on cells that had been grown for $11-25$ passages to $70 \%$ confluency. Except where noted otherwise, treatments were conducted for 24 hours at $10 \mu \mathrm{M}$. Compounds were made into $5 \mathrm{mM}$ stocks on the day of treatment in $0.9 \% \mathrm{NaCl}$ (cisplatin), DMF $(\mathbf{4}, \mathbf{7}, \mathbf{8}, \mathbf{1 0}, \mathbf{1 1}, \mathbf{1 2}, \mathbf{1 3}, \mathbf{1 4})$, DMSO $(5)$, or water $(\mathbf{1}, \mathbf{2}, \mathbf{3}, \mathbf{6})$. Stock solutions were diluted into media immediately prior to drug treatment.

\section{Immunofluoresence}

Cells to be imaged were grown on coverslips (Ted Pella product no 260368, Round glass coverslips, $10 \mathrm{~mm}$ diam, $0.16-0.19 \mathrm{~mm}$ thick) as described above. After treatment, cells were washed twice with phosphate buffered saline (PBS) and fixed for 20 minutes at room temperature in 4\% paraformaldehyde in PBS. PFA was removed via aspiration and cells were then permeabilized with $0.5 \%$ Triton-X in PBS for 20 minutes at room temperature. Two tenminute blocking steps were performed with $1 \%$ bovine serum albumin (BSA) in PBST (PBS with $0.1 \%$ Tween-20). Cells were incubated for one hour in primary antibody (NPM1 Monoclonal Antibody, FC-61991, from ThermoFisher, 1:200 dilution in PBST with 1\% BSA) and 1 hour in secondary antibody (Goat Anti-Mouse IgG H\&L Alexa Fluor ${ }^{\circledR}$ 488, ab150113, Abcam, 1:1000 dilution in PBST with $1 \%$ BSA), with 3 five minute wash steps using PBST between incubations, and were washed in the same manner again before mounting slides. Coverslips were mounted on slides with ProLong ${ }^{\mathrm{TM}}$ Diamond Antifade Mountant with DAPI (Thermo Fisher) according to manufacturer's instructions.

\section{Cytotoxicity (MTT assay)}

A549 cells were seeded in 24-well plates at a density of $5 \times 10^{4}$ cells $/ \mathrm{mL}$. The following day cells were treated with $0-750 \mu \mathrm{M}$ of compound in DMEM supplemented with $10 \% \mathrm{FBS}$ and antibiotic-antimycotic. $24 \mathrm{~h}$ after treatment, compound-containing media was removed and cells washed twice with PBS. MTT in DMEM supplemented with $10 \%$ FBS and antibiotic-antimycotic was then added to cells and incubated for $3 \mathrm{~h}$. DMSO was used to dissolve the formazan crystals and absorbance at $595 \mathrm{~nm}$ was then determined using a Tecan microplate reader. Percent viability was determined by comparing to vehicle-treated control for each compound and IC50 concentration calculated from triplicate measurements using the drc package in R. ${ }^{1}$

\section{Image processing and quantification}

Images were taken using a HC PL Fluotar $63 x / 1.3$ oil objective mounted on a Leica DMi8 fluorescence microscope with Leica Application Suite X software. Quantification of NPM1 relocalization was performed in an automated fashion using a Python 3 script. Images were preprocessed in Image $J^{2,3}$ to convert the DAPI and NPM1 channels into separate 16-bit greyscale images. Between 70 and 225 cells were analyzed for each treatment group. Nuclei segmentation was determined with the DAPI images using Li thresholding functions in the Scikit- Image Python package. ${ }^{4}$ The coefficient of variation (CV) for individual nuclei, defined as the standard deviation in pixel intensity divided by the mean pixel intensity, was calculated from 
the NPM1 images using the SciPy Python package. All data were normalized to the notreatment control in each experiment. NPM1 imaging results for each compound were observed on a minimum of two separate testing days. Data are represented as boxplots generated using Seaborn within Python.

\section{Synthesis}

\section{Materials}

Cisplatin used for cell treatments was purchased from Strem Chemicals. Cisplatin used as a synthetic precursor was synthesized as described below. Oxaliplatin and carboplatin were purchased from TCl. Unless otherwise noted, all other compounds were purchased from Sigma Aldrich or TCl. Picoplatin ${ }^{5}$ and azidoplatin ${ }^{6}$ were synthesized as previously reported.

\section{Cisplatin (1)}

Cisplatin was synthesized according to previously described methods by Dhara $^{7}$ and reviewed. ${ }^{8}$ Briefly, potassium tetrachloroplatinate $(62.7 \mathrm{mg}, 0.151 \mathrm{mmol}, 1 \mathrm{eq})$ was dissolved in $180 \mu \mathrm{L}$ of water and stirred at $40^{\circ} \mathrm{C}$. Potassium iodide $(300 \mathrm{mg}, 1.807 \mathrm{mmol}, 12 \mathrm{eq})$ was dissolved separately in $500 \mu \mathrm{L}$ of water and warmed to $40^{\circ} \mathrm{C}$. $250 \mu \mathrm{L}$ of the potassium iodide solution was added dropwise to the solution containing potassium tetrachloroplatinate. After addition of potassium iodide, the solution was warmed to $70^{\circ} \mathrm{C}$. Once the solution reached $70^{\circ} \mathrm{C}$ it was removed from heat and cooled to room temperature. The solution was then filtered through celite. The filtrate was collected and used for the following reaction. A $2 \mathrm{M}$ solution of ammonium hydroxide in water $(250 \mu \mathrm{L})$ was added dropwise. The solution was allowed to stand for 30 minutes, filtered, and washed with ethanol $(x 1)$ and ether $(x 2)$. The solid was collected to yield $56.2 \mathrm{mg}$ cis-diamminediiodoplatinum(II). Silver sulfate $(37 \mathrm{mg}, 0.119 \mathrm{mmol}$, 1eq) was added to $5 \mathrm{~mL}$ of water. Cis-diamminediiodoplatinum(II) $(56.2 \mathrm{mg}, 0.116 \mathrm{mmol}$, 1eq) was added slowly. The solution was heated to $80^{\circ} \mathrm{C}$. The solution was stirred overnight. The silver iodide was filtered using celite and the filtrate collected. This solution was concentrated to $1.5 \mathrm{~mL}$. Potassium chloride (174.6 mg, $2.34 \mathrm{mmol}, 20 \mathrm{eq}$ ) was added to the solution and then heated to $80^{\circ} \mathrm{C}$. The solution was stirred at $80^{\circ} \mathrm{C}$ for another 20 minutes and cooled to room temperature. The solution was filtered and washed with ethanol $(x 1)$ and ether $(x 2)$ to yield $23.5 \mathrm{mg}(52 \%)$ cis-diamminedichloroplatinum(II). ${ }^{1} \mathrm{H}$ NMR (500 MHz, DMF-d7) $\delta 3.99(\mathrm{~s}, 6 \mathrm{H})$.

\section{Cis-(trans-1,2-diaminocyclohexane)dichloride Platinum(II) (DACH-Pt) (4)}

Cis-(trans(+/-)-1,2-diaminocyclohexane)dichloride Platinum(II) was prepared using general methods previously described. ${ }^{8}$ Potassium tetrachloroplatinate $(100.3 \mathrm{mg}, 0.242 \mathrm{mmol}$, $1 \mathrm{eq})$ was dissolved in $4 \mathrm{~mL}$ of water. Trans(+/-)-1,2-diaminocyclohexane $(29.1 \mathrm{mg}, 0.255$ $\mathrm{mmol}, 1 \mathrm{eq}$ ) was added dropwise to the dark red solution and stirred for 7.5 hours. A yellow precipitate formed. The solution was filtered and washed with ice-cold methanol (x1) and acetone $(\mathrm{x} 1)$. The yellow solid was then collected to yield $70 \mathrm{mg}(76 \%)$. ${ }^{1} \mathrm{H}$ NMR $(500 \mathrm{MHz}$, DMF-d7) $\delta 5.59$ (d, J = 7.4 Hz, 2H), 5.02 (s, 2H), 2.50 (qq, J = 11.2, 5.6, 3.8 Hz, 2H), $2.15-$ $2.04(\mathrm{~m}, 2 \mathrm{H}), 1.56(\mathrm{dd}, \mathrm{J}=7.7,3.3 \mathrm{~Hz}, 2 \mathrm{H}), 1.48(\mathrm{tt}, \mathrm{J}=11.9,5.6 \mathrm{~Hz}, 2 \mathrm{H}), 1.15(\mathrm{qd}, \mathrm{J}=11.9$, $2.9 \mathrm{~Hz}, 2 \mathrm{H}) .{ }^{195} \mathrm{Pt}$ NMR (107 MHz, DMF-d7) $\delta-2270.32$.

\section{Cis-(diammine)oxalic acid Platinum(II) (DOAP) (5)}

Cis-(diammine)oxalic acid Platinum(II) was prepared using general methods previously described. ${ }^{8}$ Sodium oxalate was prepared by introducing excess sodium hydroxide to oxalic acid and filtering the resulting solid. Cis-(diammine)diiodo platinum(II) (92.3 $\mathrm{mg}, 0.193 \mathrm{mmol}, 1$ eq) was dissolved in $5 \mathrm{~mL}$ water. Silver nitrate $(82 \mathrm{mg}, 0.4823 \mathrm{mmol}, 2.5 \mathrm{eq})$ was added and the reaction stirred overnight protected from light. The reaction was then filtered through celite and the filtrate collected. Sodium oxalate $(26 \mathrm{mg}, 0.194 \mathrm{mmol}, 1 \mathrm{eq})$ was added to the filtrate and 
the reaction was stirred overnight and protected from light. The resulting light grey solid was filtered from the solution and washed with water $(2 \mathrm{x})$ and methanol $(\mathrm{x} 2)$. Yield $33.3 \mathrm{mg}(54 \%) .{ }^{1} \mathrm{H}$ NMR (500 MHz, DMSO-d6) $\delta 4.27$ (s, 6H). ${ }^{13} \mathrm{C}$ NMR (126 MHz, DMSO-d6) $\delta ~ 166.38 . ~{ }^{195} \mathrm{Pt}$ NMR (107 MHz, DMSO-d6) $\delta-1743.33$.

\section{Cis-(trans-1,2-diaminocyclohexane)1,2-ethylenediamine Platinum(II) (DACH-En) (6)}

Cis-(trans(+/-)-1,2-diaminocyclohexane)dichloro platinum(II) $(62 \mathrm{mg}, 0.163 \mathrm{mmol}$, 1eq) was dissolved in $5 \mathrm{~mL}$ of water. 1,2-diaminoethane (32 $\mathrm{mg}, 0.533 \mathrm{mmol}, 3.2 \mathrm{eq})$ was added to the solution and refluxed for two days. The solution was then cooled room temperature over 24 hours. Solution was then evaporated to yield a yellow solid. ${ }^{1} \mathrm{H}$ NMR $(500 \mathrm{MHz}$, Deuterium Oxide) $\delta 3.31(\mathrm{t}, J=5.8 \mathrm{~Hz}, 1 \mathrm{H}), 3.05(\mathrm{t}, J=5.8 \mathrm{~Hz}, 1 \mathrm{H}), 2.97(\mathrm{~s}, 2 \mathrm{H}), 2.72-2.64(\mathrm{~m}, 4 \mathrm{H}), 2.47$ - $2.39(\mathrm{~m}, 2 \mathrm{H}), 2.09(\mathrm{dt}, J=12.8,2.0 \mathrm{~Hz}, 2 \mathrm{H}), 1.67-1.60(\mathrm{~m}, 2 \mathrm{H}), 1.41-1.28(\mathrm{~m}, 2 \mathrm{H}), 1.20$ $(\mathrm{td}, J=9.4,8.9,4.0 \mathrm{~Hz}, 2 \mathrm{H}) .{ }^{13} \mathrm{C}$ NMR $\left(126 \mathrm{MHz}, \mathrm{D}_{2} \mathrm{O}\right) \delta 61.17,46.83,40.43,32.14,23.92$. ${ }^{195} \mathrm{Pt} \mathrm{NMR}(107 \mathrm{MHz}, \mathrm{D} 2 \mathrm{O}) \delta-3002.42$. TOF MS ES+ for $\mathrm{m} / \mathrm{z}[(\mathrm{M})]^{2+} \mathrm{C}_{8} \mathrm{H}_{21} \mathrm{Pt}$ calculated: 368.1414 found: $368.1403\left(\left[(\mathrm{M}]^{2+}\right)\right.$.

\section{Cis-(1,2-diaminoethylene)dichloride Platinum(II) (Plat-En) (7)}

Cis-(1,2-diaminoethylene)dichloride Platinum(II) was prepared using general methods previously described. ${ }^{8}$ Potassium tetrachloroplatinate $(66 \mathrm{mg}, 0.159 \mathrm{mmol}, 1 \mathrm{eq})$ was dissolved in $500 \mu \mathrm{L}$ of water. 1,2-diaminoethane $(9.36 \mathrm{mg}, 0.156 \mathrm{mmol}, 1 \mathrm{eq})$ was added to the dark red solution and allowed to stir at room temperature for 12 hours. A yellow precipitate formed. The solution was filtered and washed with ice-cold $0.1 \mathrm{M} \mathrm{HCl}(\mathrm{x} 1)$, ethanol $(x 1)$, and ether $(x 1)$. The yellow solid was collected to yield $27.5 \mathrm{mg}(53 \%) .{ }^{1} \mathrm{H}$ NMR $(500 \mathrm{MHz}$, DMF-d7) $\delta 5.38(\mathrm{~s}, 4 \mathrm{H})$, 2.61 (s, 4H). ${ }^{13} \mathrm{C}$ NMR (126 MHz, DMF-d7) $\delta 50.52 . ~{ }^{195} \mathrm{Pt}$ NMR (107 MHz, DMF-d7) $\delta-2309.12$.

\section{Cis-(2,3-diaminopropane)dichloride Platinum(II) (Plat-MeEn) (8)}

Cis-(2,3-diaminopropane)dichloride Platinum(II) was prepared according to previously reported methods and used as a mixture of isomers. ${ }^{9}$ Potassium tetrachloroplatinate (34 mg, $0.082 \mathrm{mmol}, 1 \mathrm{eq}$ ) was dissolved in $1 \mathrm{ml}$ water and heated at $50{ }^{\circ} \mathrm{C}$. Excess potassium iodide $(40$ $\mathrm{mg}, 0.24 \mathrm{mmol}$, 3eq) was dissolved in $0.5 \mathrm{~mL}$ water and added dropwise to the platinum. The solution was stirred for 10 minutes and became black. To the stirring solution, 1,2-diamino propane $(7 \mu \mathrm{L}, 0.08 \mathrm{mmol}, 1 \mathrm{eq})$ was added and the solution was stirred for 40 minutes. Yellow precipitate formed immediately. The solution was cooled to room temperature and filtered. The solid was washed with ice-cold ethanol (1x) and ether (1x).

The solid was dissolved in $2 \mathrm{ml}$ water and silver nitrate $(28 \mathrm{mg}, 0.16 \mathrm{mmol}, 2 \mathrm{eq})$ was added. The reaction was stirred for 2 days protected from light. The solution was filtered through celite and concentrated to $1 \mathrm{ml}$. Excess potassium chloride $(120 \mathrm{mg}, 1.61 \mathrm{mmol}, 20 \mathrm{eq})$ was added rapidly to the concentrated solution and the mixture was stirred at $50{ }^{\circ} \mathrm{C}$ for 1 hour. The resulting yellow solid was filtered and washed with methanol $(1 \mathrm{x})$ and ether $(1 \mathrm{x}) .{ }^{1} \mathrm{H}$ NMR $(500$ $\left.\mathrm{MHz}, \mathrm{DMF}-d_{7}\right) \delta 5.74(\mathrm{~s}, 1 \mathrm{H}), 5.55(\mathrm{~d}, J=40.1 \mathrm{~Hz}, 2 \mathrm{H}), 5.22(\mathrm{~s}, 1 \mathrm{H}), 3.30-3.17(\mathrm{~m}, 1 \mathrm{H}), 2.89-$ $2.80(\mathrm{~m}, 1 \mathrm{H}), 2.66(\mathrm{td}, J=8.2,6.1,3.1 \mathrm{~Hz}, 1 \mathrm{H}), 1.53(\mathrm{~d}, J=6.5 \mathrm{~Hz}, 3 \mathrm{H}) .{ }^{13} \mathrm{C}$ NMR $(126 \mathrm{MHz}$, DMSO) $\delta 56.00,52.41,16.38$.

\section{Cis-(trans-1,2-diaminocyclopentane)dichloride Platinum(II) (Penta-Pt) (9)}

Cis-(trans-1S,2S-diaminocyclopentane)dichloride Platinum(II) was synthesized according to previously published methods. ${ }^{10}$ Potassium tetrachloroplatinate $(101 \mathrm{mg}, 0.243$ $\mathrm{mmol}, 1 \mathrm{eq}$ ) was dissolved in $2 \mathrm{~mL}$ of water. $(1 S, 2 S)$-trans-diaminocyclopentane dihydrochloride (43.1 $\mathrm{mg}, 0.249 \mathrm{mmol}, 1 \mathrm{eq}$ ) was added and stirring continued. $73 \mathrm{mg}$ of 1,8Diazabicyclo[5.4.0]undec-7-ene (DBU) $(0.482 \mathrm{mmol}$, 2eq) was added to the solution. A yellow precipitate formed. The solution was filtered and washed with ethanol (x1) and ether (x2). The 
yellow solid was collected to yield $50.5 \mathrm{mg}(57 \%) .{ }^{1} \mathrm{H}$ NMR (500 MHz, DMF-d7) $\delta 5.18(\mathrm{~s}, 2 \mathrm{H})$, $5.00(\mathrm{~s}, 2 \mathrm{H}), 3.41-3.31(\mathrm{~m}, 2 \mathrm{H}), 2.16(\mathrm{tdd}, \mathrm{J}=9.6,8.0,5.3 \mathrm{~Hz}, 2 \mathrm{H}), 1.78-1.64(\mathrm{~m}, 2 \mathrm{H}), 1.63$ $-1.48(\mathrm{~m}, 1 \mathrm{H}) .{ }^{13} \mathrm{C}$ NMR $(126 \mathrm{MHz}, \mathrm{DMF}-\mathrm{d} 7) \delta 70.21,26.73,23.93 .{ }^{195} \mathrm{Pt}$ NMR $(107 \mathrm{MHz}$, DMFd7) $\delta-1987.96$.

\section{Cis-(1,2-phenylenediamine)dichloride Platinum(II) (Benza-Pt) (10)}

Cis-(1,2-phenylenediamine)dichloride Platinum(II) was prepared using general methods previously described. ${ }^{8}$ Potassium tetrachloroplatinate $(103 \mathrm{mg}, 0.248 \mathrm{mmol}, 1 \mathrm{eq}$ ) was dissolved in $1 \mathrm{~mL}$ of water. A dark red solution formed. 1,2-phenylenediamine $(26.8 \mathrm{mg}, 0.248 \mathrm{mmol}$, 1eq) was added and stirring continued for 6 hours. The solution was filtered and washed with ice-cold ethanol $(x 1)$ and ether $(x 2)$. The dark yellow/brown solid was collected with a yield of $89.8 \mathrm{mg}(96 \%) .{ }^{1} \mathrm{H}$ NMR $\left(500 \mathrm{MHz}, \mathrm{DMF}-d_{7}\right) \delta 7.72(\mathrm{~s}, 2 \mathrm{H}), 7.46(\mathrm{dd}, J=5.9,3.5 \mathrm{~Hz}, 1 \mathrm{H}), 7.28$ (dd, $J=6.0,3.4 \mathrm{~Hz}, 1 \mathrm{H}) .{ }^{13} \mathrm{C}$ NMR $\left(126 \mathrm{MHz}\right.$, DMF-d7) $\delta 144.76,128.85,127.36 .{ }^{195} \mathrm{Pt} \mathrm{NMR}(107 \mathrm{MHz}$, DMF-d7) $\delta$-2199.18.

\section{Cis-(2-aminomethylpyridine)dichloride Platinum(II) (APP) (12)}

Cis-(2-aminomethylpyridine)dichloride Platinum(II) was synthesized according to previously described methods. ${ }^{11}$ A solution of 2-picolylamine $(120 \mu \mathrm{L}, 0.075 \mathrm{mmol}$, $1 \mathrm{eq})$ was made in $1.2 \mathrm{~mL}$ water. Potassium tetrachloroplatinate $(55 \mathrm{mg}, 0.133 \mathrm{mmol}$, 2eq) was dissolved in $1.2 \mathrm{~mL}$ water. The platinum solution was added to the 2-picolylamine and the $\mathrm{pH}$ was adjusted to $\mathrm{pH} 5$ using concentrated $\mathrm{HCl}$. The reaction was stirred for 4 hours. The $\mathrm{pH}$ of the solution was adjusted during the reaction to be around $\mathrm{pH} 5-6$ using $1 \mathrm{M} \mathrm{NaOH}$. The resulting yellow solid was filtered and washed with water $(2 \mathrm{x})$ to yield $38.7 \mathrm{mg}(89 \%) .{ }^{1} \mathrm{H}$ NMR $(500 \mathrm{MHz}$, DMF- $\left.d_{7}\right) \delta 9.43(\mathrm{~d}, J=5.3 \mathrm{~Hz}, 1 \mathrm{H}), 8.37$ (t, $\left.J=7.7 \mathrm{~Hz}, 1 \mathrm{H}\right), 7.91(\mathrm{~d}, J=7.8 \mathrm{~Hz}, 1 \mathrm{H}), 7.72$ (t, $J=$ $6.7 \mathrm{~Hz}, 1 \mathrm{H}), 6.42(\mathrm{~s}, 2 \mathrm{H}), 4.55(\mathrm{t}, J=5.9 \mathrm{~Hz}, 2 \mathrm{H})$.

\section{Measurement of partition coefficients}

Water was mixed with octanol for 24 hours and left to stand for an additional 24 hours to obtain water-saturated octanol and octanol-saturated water that were used for determining partition coefficients. Measurements of the partition coefficients were performed using classical shakeflask method according to OECD guidelines. ${ }^{12}$ Platinum complexes were dissolved in octanolsaturated water at concentrations between $0.5 \mathrm{mM}$ and $5 \mathrm{mM}$. The octanol-saturated water mixtures were mixed with water-saturated octanol in a 1:1 ratio and vortexed for 30 minutes. ${ }^{13}$ The mixtures were then centrifuged and $0.5 \mathrm{~mL}$ samples of both phases were collected and quantified using RP-HPLC as described by Klose et al. ${ }^{10}$ An isocratic method was used for HPLC analysis with water and methanol. Methanol concentrations ranged from $10 \%$ to $30 \%$ with $30 \%$ being used for more hydrophobic compounds. The area of absorbance was used to calculate the ratio $(P)$ of platinum in octanol and water as this area is proportional to the concentration according to the Lambert-Beer law. The column was washed with $95 \%$ methanol $5 \%$ water between each octanol sample and equilibrated before the next sample was introduced. The stock solution of each platinum compound was compared to the total from octanol and water samples as a check of this method. This procedure to calculate logP was performed in triplicate and standard deviations were determined.

\section{Computations}

Computations were performed as previously reported. ${ }^{14}$ Briefly, compounds were optimized using density functional theory (DFT) in Gaussian09. ${ }^{15}$ Optimizations to geometry were 
performed using a RMS force convergence criterion of $10^{-5}$ hartree. The electronic wavefunction was minimized using GGA functional PBE, ${ }^{16,17}$ with the DEF2TZP basis set. We did not explicitly include relativistic effects as these were not expected to impact the geometries of the compounds significantly. ${ }^{18}$

Two measures of size were used for the compounds: volume and longest vector between the platinum atom and the surface of the molecule. The vector represents the main steric component of the non-labile ligand of each compound to provide a direct comparison especially when comparing compounds that do not share the same aquation-labile ligand identity. In order to quantitatively assess the size of the molecules we used the presence of electric field, as derived from the electrostatic potential, to signify the location of the chemical system. DFT yields the electrostatic potential of the optimized, non-hydrolyzed compound structures and tools previously developed and reported were used to analyze the electrostatic potential of a chemical system. ${ }^{19}$ We used the same file format to analyze the electrostatic potential and the result was the electrostatic potentials of the optimized structures were computed by minimizing the electronic wavefunction using $500 \mathrm{eV}$ planewave cutoff, a gamma only k-grid, and a PBE functional utilizing a plane-augmented wave $(P A W)^{20,21}$ basis as implemented in the Vienna $A b$ Initio Software Package. ${ }^{22-25}$

All compounds were calculated in a sufficiently large computational box to minimize selfinteraction. The electric field is the gradient of the electrostatic potential; therefore, the electric field includes the direction of the greatest increase in electrostatic potential. DFT calculations return electrostatic potential values on the order of $10^{-6} \mathrm{eV}$, therefore a change in less than $10^{-5}$ $\mathrm{eV}$ is considered negligible. This approach is based on previous atomic radii calculations which employ negligible change in electron density to assess the size of atoms. We used this measurement of the electric field and definition of the surface of the compound to find the total volume of the compounds as well as the longest vector from the platinum center to the farthest edge of the non-labile ligand.

\section{References:}

(1) Ritz, C.; Baty, F.; Streibig, J. C.; Gerhard, D. Dose-Response Analysis Using R. PLOS ONE 2015, 10, e0146021.

(2) Schindelin, J.; Arganda-Carreras, I.; Frise, E.; Kaynig, V.; Longair, M.; Pietzsch, T.; Preibisch,

S.; Rueden, C.; Saalfeld, S.; Schmid, B.; Tinevez, J.; White, D. J.; Hartenstein, V.; Eliceiri, K.; Tomancak, P.; Cardona, A.. Fiji: An Open-Source Platform for Biological-Image Analysis. Nat. Methods 2012, 9, 676-682.

(3) Rueden, C. T.; Schindelin, J.; Hiner, M. C.; DeZonia, B. E.; Walter, A. E.; Arena, E. T.; Eliceiri, K. W. ImageJ2: ImageJ for the next Generation of Scientific Image Data. BMC Bioinformatics 2017, 18, 529.

(4) Walt, S. van der; Schönberger, J. L.; Nunez-Iglesias, J.; Boulogne, F.; Warner, J. D.; Yager, N.; Gouillart, E.; Yu, T. Scikit-Image: Image Processing in Python. PeerJ 2014, 2, e453.

(5) Okada, T.; El-Mehasseb, I. M.; Kodaka, M.; Tomohiro, T.; Okamoto, K.; Okuno, H. Mononuclear Platinum(II) Complex with 2-Phenylpyridine Ligands Showing High Cytotoxicity against Mouse Sarcoma 180 Cells Acquiring High Cisplatin Resistance. J. Med. Chem. 2001, 44, 4661-4667.

(6) Wirth, R.; White, J. D.; Moghaddam, A. D.; Ginzburg, A. L.; Zakharov, L. N.; Haley, M. M.; DeRose, V. J. Azide vs. Alkyne Functionalization in Pt(II) Complexes for Post-Treatment Click Modification: Solid State Structure, Fluorescent Labeling, and Cellular Fate. J. Am. Chem. Soc. 2015, 137, 15169-15175. 
(7) Dhara, S.C. A Rapid Method for the Synthesis of Cis-[Pt $\left.\left(\mathrm{NH}_{3}\right)_{2} \mathrm{Cl}{ }_{2}\right]$. Indian J Chem 1970, 8, 193.

(8) Wilson, J. J.; Lippard, S. J. Synthetic Methods for the Preparation of Platinum Anticancer Complexes. Chem. Rev. 2014, 114, 4470-4495.

(9) Fanizzi, F. P.; Intini, F. P.; Maresca, L.; Natile, G.; Quaranta, R.; Coluccia, M.; Di Bari, L.; Giordano, D.; Mariggió, M. A. Biological Activity of Platinum Complexes Containing Chiral Centers on the Nitrogen or Carbon Atoms of a Chelate Diamine Ring. Inorganica Chim. Acta 1987, 137, 45-51.

(10) Garbutcheon-Singh, K. B.; Leverett, P.; Myers, S.; Aldrich-Wright, J. R. Cytotoxic Platinum(II) Intercalators That Incorporate 1R,2R-Diaminocyclopentane. Dalton Trans. 2013, 42, 918-926.

(11) Brunner, H.; Schellerer, K.-M. New Porphyrin Platinum Conjugates for the Cytostatic and Photodynamic Tumor Therapy. Inorganica Chim. Acta 2003, 350, 39-48.

(12) OECD. Test No. 107: Partition Coefficient (n-Octanol/Water): Shake Flask Method, OECD Guidelines for the Testing of Chemicals, Section 1; OECD Publishing: Paris, 1995.

(13) Wilson, J. J.; Lippard, S. J. In Vitro Anticancer Activity of Cis-Diammineplatinum(II) Complexes with $\beta$-Diketonate Leaving Group Ligands. J. Med. Chem. 2012, 55, 5326-5336.

(14) McDevitt, C. E.; Yglesias, M. V.; Mroz, A. M.; Sutton, E. C.; Yang, M. C.; Hendon, C. H.; DeRose, V. J. Monofunctional Platinum(II) Compounds and Nucleolar Stress: Is Phenanthriplatin Unique? J. Biol. Inorg. Chem. 2019, 24, 899-908.

(15) Frisch, M. J.; Trucks, G. W.; Schlegel, H. B.; Scuseria, G. E.; Robb, M. A.; Cheeseman, J. R.; Scalmani, G.; Barone, V.; Mennucci, B.; Petersson, G. A.; Nakatsuji, H.; Caricato, M.; Li, X.; Hratchian, H. P.; Izmaylov, A. F.; Bloino, J.; Zheng, G.; Sonnenberg, J. L.; Hada, M.; Ehara, M.; Toyota, K.; Fukuda, R.; Hasegawa, J.; Ishida, M.; Nakajima, T.; Honda, Y.; Kitao, O.; Nakai, H.; Vreven, T.; Montgomery, J. A., Jr.; Peralta, J. E.; Ogliaro, F.; Bearpark, M.; Heyd, J. J.; Brothers, E.; Kudin, K. N.; Staroverov, V. N.; Kobayashi, R.; Normand, J.; Raghavachari, K.; Rendell, A.; Burant, J. C.; Iyengar, S. S.; Tomasi, J.; Cossi, M.; Rega, N.; Millam, J. M.; Klene, M.; Knox, J. E.; Cross, J. B.; Bakken, V.; Adamo, C.; Jaramillo, J.; Gomperts, R.; Stratmann, R. E.; Yazyev, O.; Austin, A. J.; Cammi, R.; Pomelli, C.; Ochterski, J. W.; Martin, R. L.; Morokuma, K.; Zakrzewski, V. G.; Voth, G. A.; Salvador, P.; Dannenberg, J. J.; Dapprich, S.; Daniels, A. D.; Farkas, Ö.; Foresman, J. B.; Ortiz, J. V.; Cioslowski, J.; Fox, D. J.. Gaussian09; Gaussian Inc. Wallingford CT, 2016.

(16) Perdew, J. P.; Burke, K.; Ernzerhof, M. Generalized Gradient Approximation Made Simple. Phys. Rev. Lett. 1996, 77, 3865-3868.

(17) Perdew, J.; Burke, K.; Ernzerhof, M. Errata: Generalized Gradient Approximation Made Simple. Phys. Rev. Lett. 1997, 78, 1396.

(18) Pansini, F.; Neto, A.; de Campos, M.; de Aquino R. Effects of All-Electron Basis Sets and the Scalar Relativistic Corrections in the Structure and Electronic Properties of Niobium Clusters. J. Phys. Chem. A 2017, 121, 5728-5734.

(19) Butler, K.; Hendon, C.; Walsh, A. Electronic Chemical Potentials of Porous Metal-Organic Frameworks. J. Am. Chem. Soc. 2014, 136, 2703-2706.

(20) Blochl, P. Projector Augmented-Wave Method. Phys. Rev. B 1994, 50.

(21) Kresse, G.; Joubert, D. From Ultrasoft Pseudopotentials to the Projector Augmented-Wave Method. Phys. Rev. B 1999, 59, 1758. 
(22) Kresse, G.; Hafner, J. Ab Initio Molecular Dynamics for Liquid Metals. Phys. Rev. B 1993, 47, 558.

(23) Kresse, G.; Furthmüller, J. Efficiency of Ab-Initio Total Energy Calculations for Metals and Semiconductors Using a Plane-Wave Basis Set. Comput. Mater. Sci. 1996, 6, 15-50.

(24) Kresse, G.; Furthmuller, J. Efficient Iterative Schemes for Ab Initio Total-Energy Calculations Using a Plane-Wave Basis Set. Phys. Rev. B 1996, 54, 11169.

(25) Kresse, G.; Hafner, J. Ab Initio Molecular-Dynamics Simulation of the Liquid-Metal-Amorphous-Semiconductor Transition in Germanium. Phys. Rev. B 1994, 49, 14251-14269. 